\title{
Atividade fisiológica da cana-de-açúcar após a aplicação de herbicidas em pré- emergência ${ }^{1}$
}

\author{
Physiological activity of sugarcane after the application of pre-emergence \\ herbicides
}

Autieres Teixeira Faria ${ }^{2}$; Douglas Teixeira Saraiva ${ }^{3}$; Ariana Mota Pereira ${ }^{4}$; Paulo Roberto Ribeiro Rocha $^{5}$; Antonio Alberto da Silva ${ }^{6}$; Daniel Valadão Silva ${ }^{7}$ : Evander Alves Ferreira ${ }^{8}$; Sarah da Silva Benevenute ${ }^{9}$

Resumo - Objetivou-se neste trabalho avaliar as características fisiológicas da cana-de-açúcar após aplicação de herbicidas em pré-emergência. Para isso, foi conduzido um experimento em esquema fatorial 2x5, onde o fator A constituiu-se das cultivares RB 867515 e SP 81-3250, e o fator B da aplicação em pré-emergência do tebuthiuron, diuron, ametryn, a mistura formulada diuron + hexazinone e uma testemunha sem herbicidas. O delineamento utilizado foi inteiramente casualizado, com quatro repetições. As avaliações foram realizadas aos 90 dias após a aplicação dos herbicidas. A concentração interna de carbono $(C \mathrm{i})$, a relação carbono interno e externo $(\mathrm{Ci} / \mathrm{Ca})$ e o índice SPAD das cultivares de cana-de-açúcar não foram afetadas pela aplicação em pré-emergência dos herbicidas. No entanto, a condutância estomática $(g s)$, a taxa respiratória $(E)$ e a taxa fotossintética $(A)$ da RB 867515 foram reduzidas quando tratadas com tebuthiuron. A $A$ e a eficiência no uso da água (EUA) da cultivar RB 867515 foi alterada negativamente pela aplicação do ametryn. Conclui-se que existe diferença na sensibilidade dos genótipos de cana-deaçúcar aos herbicidas, sendo que a SP 81-3250 mostrou-se mais tolerante. A aplicação do ametryn e tebuthiuron reduz a $A$ da RB 867515.

Palavras-chaves: Seletividade, estresse químico, variedades, Saccharum spp.

Abstract - The objective of this study was to evaluate the physiological characteristics of sugarcane after application of pre-emergence herbicides. For this, an experiment was conducted in a 2x5 factorial scheme, where the first factor consisted of cultivates RB 867515 and SP 813250 , and factor $\mathrm{B}$ of the pre-emergence application of tebuthiuron, diuron, ametryn, a formulated mixture diuron + hexazinone and a control without herbicides. The experimental

\footnotetext{
${ }^{1}$ Recebido para publicação em 07/08/2013 e aceito em 13/01/2014.

2 Doutorando do Programa de Pós Graduação em Fitotecnia da Universidade Federal de Viçosa. Avenida Peter Henry Rolfs, s/n, Campus UFV, 36.570-000, Viçosa, Minas Gerais, Brasil. autieresteixeira@ yahoo.com.br.

${ }^{3}$ Acadêmico do curso de Zootecnia da Universidade Federal de Viçosa. douglas.saraiva @ufv.br.

4 Mestranda do Programa de Pós Graduação em Fisiologia Vegetal da Universidade Federal de Viçosa. ariana.mota@ufv.br.

${ }^{5}$ Docente da Universidade Federal de Roraima. pauloagro01@yahoo.com.br.

${ }^{6}$ Docente do Departamento de Fitotecnia da Universidade Federal de Viçosa. aasilva@ufv.br.

${ }^{7}$ Pós doutorando do Programa de Pós Graduação em Produção Vegetal da Universidade Federal de Viçosa, campus Rio Paranaíba. danielvaladaos@ yahoo.com.br.

${ }^{8}$ Pós doutorando do Programa de Pós Graduação em Produção Vegetal da Universidade Federal dos Vales do Jequitinhonha e Mucuri. evanderalves@gmail.com.

${ }^{9}$ Acadêmica do curso de Agronomia da Universidade Federal de Viçosa. sbenevenute@ gmail.com.
} 
design was completely randomized, with four replications. The internal concentration of carbon $(\mathrm{Ci})$, internal and external carbon $(\mathrm{Ci} / \mathrm{Ca})$ and SPAD index of cultivars of sugarcane ratio were not affected by the application of pre-emergence herbicides. However, stomatal conductance ( $g \mathrm{~s})$, respiratory rate $(E)$ and the photosynthetic rate $(A)$ were reduced when treated with tebuthiuron. The $A$ and efficiency of water use (U.S.) cultivar RB 867515 was negatively altered by the application of ametryn. It is concluded that a difference in sensitivity of the genotypes of sugar cane herbicide, and the SP 81-3250 was more tolerant. The application of tebuthiuron and ametryn reduces the $A$ of $\mathrm{RB} 867515$.

Keywords: Selectivity, chemical stress, varieties, Saccharum spp.

\section{Introdução}

O Brasil destaca-se no cenário mundial como maior produtor de cana-de-açúcar sendo sua produção estimada para a safra 2012/13 de 596,63 milhões de toneladas de cana moída em uma área de 8.527,8 mil hectares representando aumento de $2,1 \%$ ou 171,7 mil hectares em relação à safra passada $(\mathrm{CONAB}, 2012)$. Para a contínua expansão do setor ainda são necessários investimentos em tecnologia tanto para aumento de produção como de eficiência.

As plantas daninhas têm constituído um dos principais problemas em canaviais brasileiros por reduzir a produtividade em até $40 \%$ (Kuva et al., 2003). Além disso, reduzem a qualidade do produto colhido e a longevidade do canavial (Kuva et al., 2003; Negrisoli et al., 2004). Esse problema é agravado pelo fato da cultura apresentar brotação e crescimento inicial lento e ser cultivada com espaçamentos entre linhas largos favorecendo o crescimento de desenvolvimento das infestantes (Kuva et al., 2000 e 2003; Procópio et al., 2003).

Entre os métodos de controle de plantas daninha, o controle químico é o mais utilizado na cultura da cana-de-açúcar e baseia na aplicação de herbicidas em pré-emergência. Essa modalidade de herbicidas apresenta maior efeito residual, onde ao mesmo tempo em que mantém a cultura livre de competição no seu período crítico de interferência, podem ser ainda uma boa alternativa para a logística de maquinário, com menores perdas por intoxicação da cultura em relação a aplicação em pós-emergência para a maioria dos herbicidas (Velini et al., 2000). Todavia, o uso desses produtos podem causar danos diretos e indiretos no crescimento e desenvolvimento das espécies cultivadas (Das et al., 2003; Rizzardi et al., 2003), efeitos estes dependentes das interações entre os herbicidas, o ambiente e a cultura, podendo ser observadas modificações na absorção de nutrientes, sintomas de intoxicação visual e alteração nos mecanismos de defesa da planta a fatores abióticos e bióticos, que não são perceptíveis e nem amplamente considerados (Rizzardi et al., 2003).

Especula-se que existem diferenças entre os diferentes materiais genéticos de canade-açúcar quanto à tolerância a herbicidas, e que este aspecto pode ser avaliado por meio de análises fisiológicas (Galon, 2010b). Diante disso, o presente trabalho teve por objetivo avaliar os efeitos de herbicidas aplicados em pré-emergência sobre as características fisiológicas de cana-de-açúcar.

\section{Material e Métodos}

$\mathrm{O}$ experimento foi conduzido em ambiente protegido. Utilizou-se como substrato um Argissolo Vermelho-Amarelo Distrófico típico, textura argilosa (53\% de argila, 27\% de silte e $20 \%$ de areia). A análise química do solo está apresentada na tabela 1. Para adequação do substrato quanto à nutrição, foram aplicados o equivalente a $250 \mathrm{~kg} \mathrm{ha}^{-1}$ de calcário dolomítico, $220 \mathrm{~kg} \mathrm{ha}^{-1}$ de superfosfato simples e $30 \mathrm{~kg} \mathrm{ha}^{-1}$ de cloreto de potássio. A adubação nitrogenada foi realizada em cobertura aos 30 dias após a emergência da cultura, na dose de $90 \mathrm{~kg} \mathrm{ha}^{-1}$ de ureia previamente dissolvida em 
água. As irrigações foram feitas diariamente, por sistema automático de microaspersão.

Tabela 1. Análise química do solo cultivado com cana-de-áçucar

\begin{tabular}{|c|c|c|c|c|c|c|c|c|c|c|c|c|c|}
\hline \multirow{2}{*}{ Solo } & pH & $\mathbf{P}$ & $\mathbf{K}$ & $\mathrm{Ca}$ & Mg & Al & $\mathbf{H}+\mathbf{A l}$ & SB & $(\mathbf{t})$ & $\mathbf{T}$ & V & $\mathbf{m}$ & MO \\
\hline & $\mathrm{H}_{2} \mathrm{O}$ & --mg d & $m^{-3}--$ & & ---- & $\mathbf{m o l}_{\mathrm{c}}$ & $\mathrm{Im}^{-3}$ & ---- & & & $--\%$ & & dag $\mathrm{kg}^{-1}$ \\
\hline & 5,2 & 14,3 & 162 & 3,6 & 0,7 & 0,1 & 3,14 & 4,71 & 4,81 & 7,85 & 60 & 2 & 3,6 \\
\hline
\end{tabular}

Análises realizadas no Laboratório de Análises de Solo Viçosa, segundo a metodologia da Empresa Brasileira de Pesquisa Agropecuária - EMBRAPA (1997); ( $\mathrm{t}$ = capacidade de troca catiônica efetiva; $\mathrm{V}$ = saturação por bases; $\mathrm{m}$ $=$ Saturação por $\mathrm{Al}^{+3} ; \mathrm{MO}=$ matéria orgânica.

O experimento foi conduzido em delineamento inteiramente casualizados com quatro repetições. Adotou-se esquema fatorial $2 \times 5$ sendo o primeiro fator constituído pelas duas cultivares, a RB 867515 e SP 81-3250; combinadas com a aplicação em préemergência de quatro herbicidas, tebuthiuron (1,2 $\mathrm{kg} \mathrm{ha}^{-1}$ i.a., Combine 500SC), diuron (3,2 $\mathrm{kg} \mathrm{ha}^{-1}$ i.a., Diuron Nortox 500SC), ametryn (3,0 $\mathrm{kg} \mathrm{ha}^{-1}$ i.a., Gesapax 500SC) e a mistura formulada diuron + hexazinone $\left(1404 \mathrm{~kg} \mathrm{ha}^{-1} \mathrm{e}\right.$ $396 \mathrm{~kg} \mathrm{ha}^{-1}$ i.a., Velpar K), mais uma testemunha sem aplicação de herbicidas de cada cultivar. As unidades experimentais foram constituídas por vasos com capacidade volumétrica de $13 \mathrm{dm}^{3}$ do substrato.

Em cada unidade experimental foram plantadas três gemas de cana-de-açúcar (RB 867515 e SP 81-3250), e aos cinco dias após o plantio efetuou-se a aplicação dos herbicidas, utilizando-se um pulverizador costal pressurizado à $\mathrm{CO}_{2}$, com uma ponta TTI 110.02, calibrado para o equivalente a $150 \mathrm{~L}$ ha $^{-1}$ de volume de calda.

Aos 90 dias após a aplicação (95 dias após o plantio) foram avaliadas as características fisiológicas da cana-de-açúcar, utilizando-se o IRGA (analisador de gases no infravermelho) da marca Li-Cor, modelo LI6400XT, sendo avaliadas a concentração de $\mathrm{CO}_{2}$ subestomática $\left(\mathrm{Ci}-\mu \mathrm{mol} \mathrm{mol}^{-1}\right)$, a taxa fotossintética $\left(A-\mu \mathrm{mol} \mathrm{m} \mathrm{m}^{-2} \mathrm{~s}^{-1}\right)$, condutância estomática de vapores de água $\left(g s-\mathrm{mol} \mathrm{m}^{-1} \mathrm{~s}^{-}\right.$ ${ }^{1}$ ), relação $\mathrm{Ci} / \mathrm{Ca} \quad$ (concentração intercelular/externa de $\mathrm{CO}_{2}$ ), taxa de transpiração $\left(E-\mathrm{mol} \mathrm{H}_{2} \mathrm{O} \mathrm{m}^{-2} \mathrm{~s}^{-1}\right)$ e calculada a eficiência do uso da água (EUA - mol $\mathrm{CO}_{2}$ mol $\mathrm{H}_{2} \mathrm{O}^{-1}$ ) da cultura. Avaliou-se também o índice SPAD, que e a determinação da taxa de clorofila presente na folha, através da medição utilizando o clorofilômetro portátil, marca Minolta, modelo SPAD-502, realizando-se as medições na primeira folha completamente expandida, no terço médio dessas plantas, com cinco medições por parcela.

Todos os dados obtidos foram submetidos à análise de variância, e as médias, quando significativas, comparadas pelo teste de Tukey a 5\% de probabilidade.

\section{Resultados e Discussão}

Contatou-se interação significativa entre os fatores cultivar de cana-de-açúcar e herbicidas para todas as variáveis, sendo desdobradas para análise dos fatores estudados.

A concentração interna de carbono $(C \mathrm{i})$ e a relação $C \mathrm{i} / C$ a das cultivares de cana-deaçúcar não foram afetadas pela aplicação em pré-emergência dos herbicidas aos 90 DAA (Tabela 2). A Ci é influenciada por fatores que reduzem o influxo de $\mathrm{CO}_{2}$ para o espaço interno das folhas devido a redução da condutância estomática. Isso geralmente ocorre pelo fechamento dos estômatos, influenciados por alguns fatores ambientais como disponibilidade hídrica, luz e energia, entre outros (Ometto et al., 2003). Essa variável também pode ser influenciada pelas espécies reativas de oxigênio, que atuam como mensageiros secundários na ativação de canais da membrana plasmática, possibilitando o influxo de cálcio, que se concentra no citossol causando fechamento estomático (Taiz \& 
Zeiger, 2004), reduzindo assim a condutância estomática (menor influxo de $\mathrm{CO}_{2}$ ). Considerando que $\mathrm{Ci} / \mathrm{Ca}$ é a relação direta entre a concentração de $\mathrm{CO}_{2}$ na câmara subestomática e a concentração de $\mathrm{CO}_{2}$ no ambiente, observa-se que, a aplicação dos herbicidas não promoveu alterações no aparato fotossintético da cana-de-açúcar.

Tabela 2- Carbono interno $\left(C \mathrm{i}-\mu \mathrm{mol} \mathrm{mol}{ }^{-1}\right)$ presente na câmara subestomática e relação $C \mathrm{i} / \mathrm{Ca}$ (concentração intercelular/externa de $\mathrm{CO}_{2}$ ) de cultivares de cana-de-açúcar 90 dias após a aplicação em pré-emergência de herbicidas.

\begin{tabular}{lcccc}
\hline \multirow{2}{*}{ Herbicidas $^{1}$} & \multicolumn{2}{c}{$\left(\mathrm{Ci}-\mu \mathrm{mol} \mathrm{mol}^{-1}\right)$} & \multicolumn{2}{c}{$\mathrm{Ci} / \mathrm{Ca}$} \\
\cline { 2 - 5 } & $\mathrm{SP} 81-3250$ & $\mathrm{RB} 867515$ & $\mathrm{SP} 81-3250$ & $\mathrm{RB} 867515$ \\
\hline Testemunha & $171,67 \mathrm{Aa}^{2}$ & $213,62 \mathrm{Aa}$ & $0,44 \mathrm{Aa}^{2}$ & $0,57 \mathrm{Aa}$ \\
Tebuthiuron & $179,73 \mathrm{Aa}$ & $161,61 \mathrm{Aa}$ & $0,46 \mathrm{Aa}$ & $0,41 \mathrm{Aa}$ \\
Diuron & $179,94 \mathrm{Aa}$ & $216,05 \mathrm{Aa}$ & $0,46 \mathrm{Aa}$ & $0,56 \mathrm{Aa}$ \\
Diuron + hexazinone & $227,63 \mathrm{Aa}$ & $208,74 \mathrm{Aa}$ & $0,57 \mathrm{Aa}$ & $0,54 \mathrm{Aa}$ \\
Ametryn & $152,39 \mathrm{Aa}$ & $219,00 \mathrm{Aa}$ & $0,39 \mathrm{Aa}$ & $0,57 \mathrm{Aa}$ \\
\hline CV $(\%)$ & \multicolumn{2}{c}{21,78} & \multicolumn{2}{c}{21,14} \\
\hline
\end{tabular}

${ }^{1}$ Tebuthiuron (1,2 kg ${ }^{-1}$ ha i.a., Combine 500SC), diuron (3,2 $\mathrm{kg} \mathrm{ha}^{-1}$ i.a., Diuron Nortox 500SC), ametryn (3,0 kg ha ${ }^{-1}$ i.a., Gesapax 500SC) e a mistura formulada diuron + hexazinone (1404 kg ha ${ }^{-1}$ e $396 \mathrm{~kg} \mathrm{ha}^{-1}$ i.a., Velpar K) aplicados em pré-emergência da cultura; ${ }^{2}$ Medias seguidas pela mesma letra maiúscula na linha e minúscula na coluna não diferem ao teste Tukey $5 \%$ de probabilidade.

$\mathrm{Na}$ ausência da aplicação dos herbicidas, constataram-se aos 90 DAA menores valores de condutância estomática $(g s)$ e taxa transpiratória $(E)$ da cultivar SP 813250 em relação a RB 867515 (Tabela 3). Todavia, após a aplicação dos herbicidas não se observou diferenças entre os genótipos, com exceção da $E$ para ametryn. De acordo com Brodribb \& Holbrook (2003), essas variáveis são influenciadas pela condutância cuticular da epiderme e pelo estado hídrico das células guardas nos estômatos sendo, também, afetadas pelo número e tamanho de estômatos e até mesmo o diâmetro da abertura do poro estomático. Deste modo, são influenciados por vários fatores climáticos e genéticos, sendo que a associação genótipo/herbicida pode determinar aqueles que sobressaem sob estresse hídrico, quando da aplicação do produto e, assim, garantir melhores produções em nível de lavoura (Galon et al., 2010b). A diferença de suscetibilidade entre as cultivares pode ser atribuída a distinção na absorção, translocação, metabolização e ou conjugação desses herbicidas na planta (Cataneo et al., 2003).
Comparando os efeitos dos herbicidas dentro de cada cultivar, observa-se que tebuthiuron foi único a reduzir a $g$ s e a $E$ da cultivar RB 867515 aos 90 DAA (Tabela 3). A redução da $g s$ pode ser devido ao fechamento dos estômatos provocado pelo herbicida (Ometto et al.,2003). Segundo Silva et al. (2007), os herbicidas como o tebuthiuron, que agem no aparato fotossintético das plantas, podem provocar redução da $E$.

Quando se compara a taxa fotossintética (A) entre as cultivares de cana-de-açúcar observa-se menor valor para SP 81-3250 tanto na comparação entre testemunhas como para o herbicida diuron + hexazinone (Tabela 4). De acordo com Ferreira et al. (2005) a tolerância dos genótipos de cana-de-açúcar a herbicidas é dependente do estádio de desenvolvimento da cultura e da dose do produto aplicado. No presente trabalho a dose aplicada foi a máxima indicada para o controle de plantas daninhas na cultura.

A $A$ da cultivar SP 81-3250 não foi alterada pelos herbicidas, enquanto que para a cultivar RB 867515 constatou-se redução da $A$ sob a aplicação dos herbicidas tebuthiuron e 
ametryn (Tabela 4). Esses resultados são contrários aos observados por Ferreira et al., (2005), Galon et al.(2010a) e Torres et al.(2012), que não constataram interferência desses herbicidas aplicados em pós-emergência sobre a cana-de-açúcar. Souza et al. (2009) avaliaram a tolerância de cultivares de cana-deaçúcar a herbicidas aplicados em pós- emergência na soqueira da cultura e observaram pequena redução no transporte de elétrons no fotossistema II após aplicação de diuron + hexazinone, sendo este um dos prováveis motivos da redução observada na $A$ da cultivar SP 81-3250 para os herbicidas tebuthiuron e ametryn.

Tabela 3 - Condutância estomática $\left(g \mathrm{~s}-\mu \mathrm{mol} \mathrm{m} \mathrm{m}^{-1} \mathrm{~s}^{-1}\right)$ e taxa transpiratória $\left(E \mu \mathrm{mol} \mathrm{H}_{2} \mathrm{O} \mathrm{m}^{-2} \mathrm{~s}^{-1}\right)$ de cultivares de cana-de-açúcar 90 dias após a aplicação em pré-emergência de herbicidas.

\begin{tabular}{|c|c|c|c|c|}
\hline \multirow[t]{2}{*}{ Herbicidas $^{1}$} & \multicolumn{2}{|c|}{$\left(g s-\mathrm{mol} \mathrm{m}^{-1} \mathrm{~s}^{-1}\right)$} & \multicolumn{2}{|c|}{$\left(E-\mathrm{mol} \mathrm{H}_{2} \mathrm{O} \mathrm{m}^{-2} \mathrm{~s}^{-1}\right)$} \\
\hline & SP 81-3250 & RB 867515 & SP 81-3250 & RB 867515 \\
\hline Testemunha & $0,16 \mathrm{Ba}$ & $0,33 \mathrm{Aa}$ & $0,0012 \mathrm{Ba}$ & $0,0021 \mathrm{Aa}$ \\
\hline Tebuthiuron & $0,15 \mathrm{Aa}$ & $0,14 \mathrm{Ab}$ & $0,0012 \mathrm{Aa}$ & $0,0010 \mathrm{Ab}$ \\
\hline Diuron & $0,14 \mathrm{Aa}$ & $0,24 \mathrm{Aab}$ & $0,0011 \mathrm{Aa}$ & 0,0018 Aab \\
\hline Diuron + hexazinone & $0,17 \mathrm{Aa}$ & $0,22 \mathrm{Aab}$ & $0,0013 \mathrm{Aa}$ & 0,0015 Aab \\
\hline Ametryn & 0,16 Aa & $0,22 \mathrm{Aab}$ & $0,0012 \mathrm{Ba}$ & $0,0022 \mathrm{Aa}$ \\
\hline $\mathrm{CV}(\%)$ & \multicolumn{2}{|c|}{29,76} & \multicolumn{2}{|c|}{28,84} \\
\hline
\end{tabular}

Tabela 4. Taxa fotossintética $\left(A \mu \mathrm{mol} \mathrm{H}_{2} \mathrm{O} \mathrm{m}^{-2} \mathrm{~s}^{-1}\right)$ e índice SPAD de cultivares de cultivares de cana-de-açúcar 90 dias após a aplicação em pré-emergência de herbicidas.

\begin{tabular}{lcccc}
\hline \multirow{2}{*}{ Herbicidas $^{1}$} & \multicolumn{2}{c}{$\left(A-\mu \mathrm{mol} \mathrm{m}^{-2} \mathrm{~s}^{-1}\right)$} & \multicolumn{2}{c}{ SPAD } \\
\cline { 2 - 5 } & $\mathrm{SP} 81-3250$ & $\mathrm{RB} 867515$ & $\mathrm{SP} 81-3250$ & $\mathrm{RB} 867515$ \\
\hline Testemunha & $20,34 \mathrm{Ba}$ & $28,22 \mathrm{Aa}$ & $50,76 \mathrm{Aa}$ & $46,73 \mathrm{Aa}$ \\
Tebuthiuron & $17,51 \mathrm{Aa}$ & $18,34 \mathrm{Ab}$ & $45,50 \mathrm{Aa}$ & $46,50 \mathrm{Aa}$ \\
Diuron & $22,17 \mathrm{Aa}$ & $21,48 \mathrm{Aab}$ & $48,70 \mathrm{Aa}$ & $47,57 \mathrm{Aa}$ \\
Diuron + hexazinone & $15,54 \mathrm{Ba}$ & $21,35 \mathrm{Aab}$ & $44,13 \mathrm{Aa}$ & $45,23 \mathrm{Aa}$ \\
Ametryn & $21,84 \mathrm{Aa}$ & $20,11 \mathrm{Ab}$ & $47,20 \mathrm{Aa}$ & $40,07 \mathrm{Aa}$ \\
\hline CV $(\%)$ & \multicolumn{2}{c}{14,47}
\end{tabular}

${ }^{1}$ Tebuthiuron $\left(1,2 \mathrm{~kg}^{-1}\right.$ ha i.a., Combine 500SC), diuron $\left(3,2 \mathrm{~kg} \mathrm{ha}^{-1}\right.$ i.a., Diuron Nortox 500SC), ametryn (3,0 kg ha ${ }^{-1}$ i.a., Gesapax 500SC) e a mistura formulada diuron + hexazinone (1404 $\mathrm{kg} \mathrm{ha}^{-1}$ e $396 \mathrm{~kg} \mathrm{ha}^{-1}$ i.a., Velpar K) aplicados em pré-emergência da cultura; ${ }^{2}$ Medias seguidas pela mesma letra maiúscula na linha e minúscula na coluna não diferem ao teste Tukey $5 \%$ de probabilidade.

A $A$ é influenciada por diversos fatores como: a diferença de concentração de $\mathrm{CO}_{2}$ nos espaços intercelulares e extracelular, o grau de abertura estomática e com a turgescência tanto das células-guarda (que controlam a abertura dos estômatos) como das células epidérmicas dos estômatos (Messinger et al., 2006). Neste sentido, qualquer efeito, causado pelos herbicidas avaliados, que leve à menor absorção ou à translocação de água pode alterar a condutância estomática e/ou mesofílica, promovendo a redução da $A$.

A aplicação dos herbicidas não influenciou o índice SPAD das cultivares de cana-de-açúcar (Tabela 4) ao 90 DAA. Esse índice permite estimar o teor de clorofila, por 
apresentar relação direta com essa, tento a vantagem de ser um metodo não destrutivo (Yadava, 1986; Marquard \& Tipton, 1987; Markwell et al., 1995). Esse resultado está de acordo com as avaliações de fitotoxicidade (dados não publicados) onde nenhum produto causou intoxicação visual nas cultivares de cana-de-açucar avaliadas.

A eficiência no uso da água $(E U A)$ da cultivar RB 867515 foi significativamente reduzida pela aplicação de ametryn (Tabela 5) aos 90 DAA. A EUA é medida pela relação entre a quantidade de água evapotranspirada por uma cultura e sua produção de matéria seca, podendo ser estimada ao invés de matéria seca, pela gs (Concenço et al., 2007, 2009). Assim, culturas mais eficientes no uso da água produzem mais matéria seca por grama de água transpirada ou fixa mais carbono por água transpirada (Baptista et al., 2001; Procópio et al., 2004). Desta maneira, menor crescimento é esperado para cultivares que apresente redução da $E U A$, conforme observado para o ametryn.

Tabela 5. Eficiência do uso da água (EUA - $\mu$ mol $\left.\mathrm{CO}_{2} \mathrm{~mol} \mathrm{H}_{2} \mathrm{O}^{-1}\right)$ de cultivares de cana-deaçúcar 90 dias após a aplicação em pré-emergência de herbicidas.

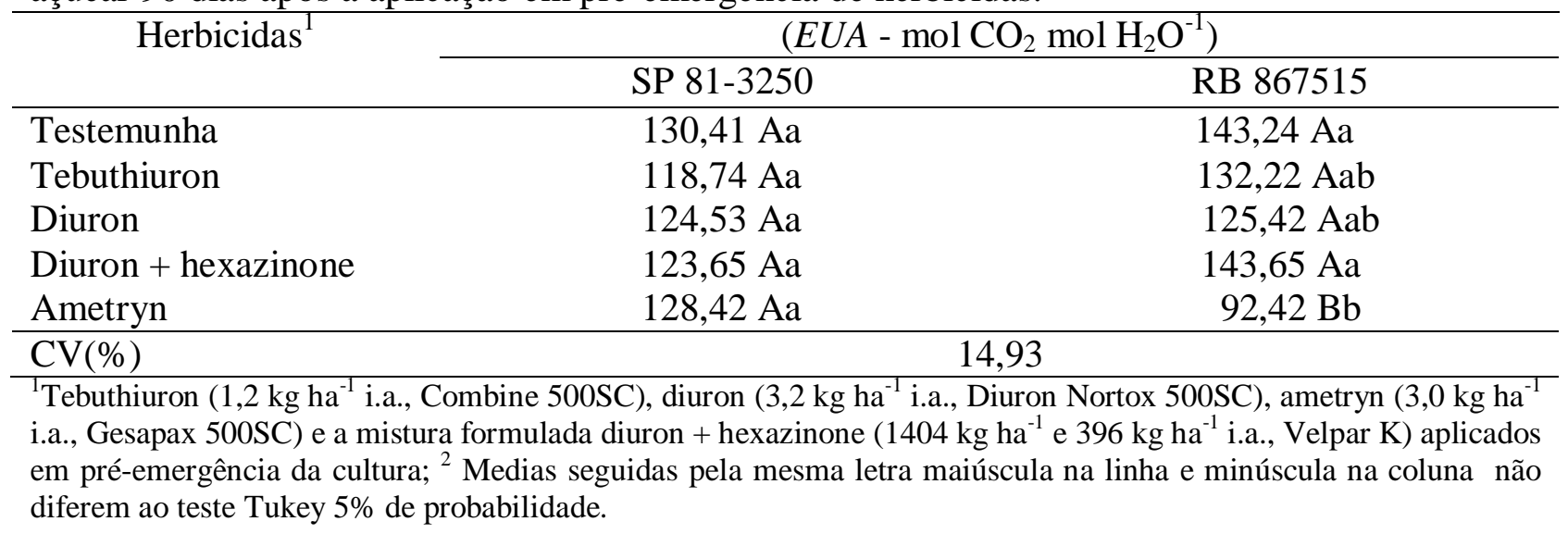

De maneira geral, aos 90 DAA em préemergência dos herbicidas tebuthiuron, diuron, ametryn e diuron + hexazinone, a concentração interna de carbono $(C \mathrm{i})$, a relação $\mathrm{Ci} / \mathrm{Ca}$ e o índice SPAD das cultivares RB 867515 e SP 81-3250 não foram significativamente afetadas. O tebuthiuron aos 90 DAA reduziu a taxa fotossintética, a condutância estomática de gases e a transpiração da cultivar RB 867515.

\section{Conclusões}

A cultivar RB 867515 apresenta maiores valores de condutância estomática, taxa transpiratória e taxa fotossintética, aos 90 dias após a aplicação dos herbicidas, do que a SP 81-3250.
As características fisiológicas da SP 813250 não foram afetadas pela aplicação dos herbicidas.

O tebuthiuron reduz a condutância estomática, a taxa transpiratória e a taxa fotossintética da cultivar RB 867515.

$\mathrm{O}$ ametryn altera negativamente a taxa fotossintética e a eficiência no uso da água da cultivar RB 867515.

\section{Agradecimentos}

A Fundação de Amparo a Pesquisa do Estado de Minas Gerais (FAPEMIG), a Coordenação de Aperfeiçoamento de Pessoal de Nível Superior (CAPES) e ao Conselho Nacional de Desenvolvimento Cientifico e Tecnológico $(\mathrm{CNPq})$ pelo apoio financeiro e as bolsas concedidas. 


\section{Referências}

AZANIA, C.A.M. et al. Seletividade de herbicidas. II - Aplicação de herbicidas em pós-emergência inicial e tardia da canadeaçúcar na época das chuvas. Planta Daninha, v.23, n.4, p.669-675, 2005.

BAPTISTA, J.M. et al. Programa nacional para o uso eficiente da água. Lisboa: Instituto Superior de Agronomia, 2001. 212 p.

BRODRIBB, T. J; HOLBROOK, N.M. Stomatal closure during leaf dehydration, correlation with other leaf physiological traits. Plant Physiol., v. 132, n. 4, p. 2166-2173, 2003.

CATANEO, A. C. et al. Glutathione Stransferase activity on the degradation of the herbicide glyphosate in maize (Zea mays) plants. Planta Daninha, v. 21, n.2, p. 307-312, 2003.

CONAB - COMPANHIA NACIONAL DE ABASTECIMENTO. Acompanhamento da safra brasileira de cana-de-açúcar. 2012. Disponível em http://www.conab.gov.br/con teudos.php? a $=1253 \&$ t. Acesso em: 25 de jul 2013.

CONCENÇO, G. et al. Uso da água em biótipos de azevém (Lolium multiflorum) em condição de competição. Planta Daninha, v.25, n.3, p.449-455, 2007.

CONCENÇO, G. et al. Uso da água por plantas de arroz em competição com biótipos de Echinochloa crusgalli resistente e suscetível ao herbicida quinclorac. Planta Daninha, v.27, n.2, p.249-256, 2009

CONSTANTIN, J. Efeitos de diferentes períodos de controle e convivência da Brachiaria decumbens Stapf. com a cana-deaçúcar (Saccharum spp.). 1993. 98f. Dissertação (Mestrado em Agronomia) Universidade Estadual Paulista, Botucatu, 1993.
DAS, A.C.; DEBNATH, A.; MUKHERJEE, D. Effect of the herbicides oxadiazon and oxyfluorfen on phosphates solubilizing microorganisms and their persistence in rice fields. Chemosphere, v.53, p.217-221, 2003.

FERREIRA, E.A. et al. Sensibilidade de cultivares de cana-de- açúcar à mistura trifloxysulfuron-sodium + ametryn. Planta Daninha, v.23, n.1, p.93-99, 2005.

GALON, L. et al. Eficiência do uso da água em genótipos de cana-de-açúcar submetidos a aplicação de herbicidas. Planta Daninha, v.28, n.4, p.777-784, $2010 \mathrm{~b}$.

GALON, L. et al. Influência de herbicidas na atividade fotossintética de genótipos de canade-açúcar. Planta Daninha, v.28, n.3, p.591597, 2010a.

HUMBLE, G.D.; HSIAO, T.C. Lightdependent influx and efflux of potassium of guard cells during stomatal opening and closing. Plant Physiol., v.46, n.3, p.483-487, 1970.

KUVA, M.A. et al. Períodos de interferência das plantas daninhas na cultura da cana-deaçúcar. I - Tiririca. Planta Daninha, v.18, n.2, p.241-251, 2000.

KUVA, M.A. et al. Períodos de interferência das plantas daninhas na cultura da cana-deaçúcar. III - Capim-braquiária (Brachiaria decumbens) e capim-colonião (Panicum maximum). Planta Daninha, v.21, n.1, p.3744, 2003.

MARKWELL, J. et al. Calibration of the Minolta SPAD-502 leaf chlorophyll meter. Photosynthesis Research, v.46, n.3, p.467472,1995.

MARQUARD, R.D.; TIPTON, J.L.; Relationship between extractable chlorophyll and an in situ method to estimate leaf greenness. Horticuture Science, v.22, p.13$27,1987$. 
MESSINGER, S.M. et al. Evidence for involvement of photosynthetic processes in the stomatal response to $\mathrm{CO} 2$. Plant Physiology, v.140, n.2, p.771-778, 2006.

MONQUERO, P.A. et al. Eficiência de herbicidas pré-emergentes após períodos de seca. Planta Daninha, v.26, n.1, p.185-193, 2008.

NEGRISOLI, E. et al. Seletividade de herbicidas aplicados em pré-emergência na cultura da cana-de-açúcar tratada com nematicidas. Planta Daninha, v.22, n.4, p.567$575,2004$.

OMETTO J.P.H.B. et al. Variação temporal do isótopo estável do carbono em material arbóreo em florestas da região Amazônica. In: CONGRESSO BRASILEIRO DE ECOLOGIA, 4., 2003, Fortaleza. Anais... Rio Claro: Sociedade de Ecologia do Brasil, 2003.

PROCOPIO, S.O. et al. Manejo de Plantas Daninhas na cultura da cana-de-açúcar. Viçosa: Universidade Federal de Viçosa, 2003. 150 p.

PROCÓPIO, S.O. et al. Manejo e controle de plantas daninhas em cana-de-açúcar. In: VARGAS, L.; ROMAN, E.S. (Eds.). Manual de manejo e controle de plantas daninhas. Bento Gonçalves: Embrapa Uva e Vinho, 2004. p.397-452

RIZZARDI, M.A. et al. Ação de herbicidas sobre mecanismos de defesa das plantas aos patógenos. Ciência Rural, v.33, n.5, p.957965, 2003.

SANTOS, G. et al Eficácia e seletividade do herbicida imazapic isolado ou associado a outros herbicidas aplicado com e sem cobertura de palha de cana-de-açúcar. Revista Brasileira de Herbicidas, v.8, n.3, p.75-84, 2009.

SILVA, A.A. et al. Competição entre plantas daninhas e culturas. In: SILVA, A. A.; SILVA, J. F. (Ed.). Tópicos em manejo de plantas daninhas. Viçosa, MG: Sociedade Brasileira de Ciência do Solo, 2007. p.17-61.
SOUZA, J.R. et al. Tolerância de cultivares de cana-de-açúcar a herbicidas aplicados em pósemergência. Bragantia, v.68, n.14, p.873-884, 2009.

TAIZ, L.; ZEIGER, E. Plant physiology. Sunderland: Sinauer, 2006. 705p.

TORRES, L.G. et al. Alterações nas características fisiológicas de cultivares de cana-de-açúcar submetida à aplicação de herbicidas; Planta Daninha, v.30, n.3, p.581587, 2012.

VELINI E.D. et al. Avaliação da seletividade da mistura de oxyfluorfen e ametryne, aplicada em pré ou pós-emergência, a dez variedades de cana-de-açúcar (cana-planta). Planta Daninha, v.18, n.1, p. 123-134, 2000.

YADAVA, U.L. A rapid and nondestructive method to determine chlorophyll in intact leaves. HortScience, v.21, p.1449-1450, 1986. 